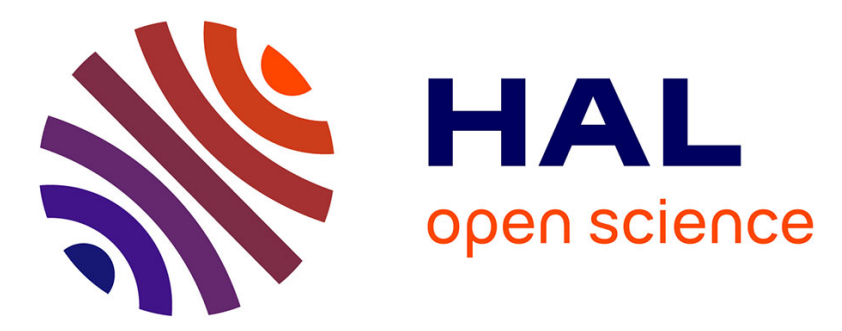

\title{
Introduction to several papers on special section of 'The Time varying Sun'
}

\author{
Christine Amory-Mazaudier, G. Gregori, W. Schroder
}

\section{To cite this version:}

Christine Amory-Mazaudier, G. Gregori, W. Schroder. Introduction to several papers on special section of 'The Time varying Sun'. Journal of Atmospheric and Solar-Terrestrial Physics, 2009, 17-18, pp.1681-1682. hal-00979612

\section{HAL Id: hal-00979612 \\ https://hal.sorbonne-universite.fr/hal-00979612}

Submitted on 16 Apr 2014

HAL is a multi-disciplinary open access archive for the deposit and dissemination of scientific research documents, whether they are published or not. The documents may come from teaching and research institutions in France or abroad, or from public or private research centers.
L'archive ouverte pluridisciplinaire HAL, est destinée au dépôt et à la diffusion de documents scientifiques de niveau recherche, publiés ou non, émanant des établissements d'enseignement et de recherche français ou étrangers, des laboratoires publics ou privés. 
Introduction to several papers on special section of 'The Time varying Sun'

By Amory-Mazaudier, C; G. Gregori, W. Schröder

Journal of Atmosph. and Solar Terr. Phys, 71, Vol 17-18, 1681-1682, 2009

The Sun is at the origin of life on the Earth, and it influences all the Earth's environment, human life, climate, geomagnetism as well as many new technologies systems as for example navigation system. This is why the time varying sun deserves to a transdisciplinary approach of many topics. In the following 8 papers, we will consider the sun itself its relation with the earth (geomagnetism and climate).

The Sun is a non solid magnetized moving body under the laws of the celestial mechanics. Its time varying scales are multiple from the solar flare time scale of several seconds, to time scale of 11 years (sunspot-wolf cycle),22 years (Schwabe cycle), century millennium, 100000 years, millions years and more.

At the present time we are at a turning point, on one hand there are old data on the time varying sun recorded since centuries or more (as for example the sunspot number) or derived from earth's magnetic field observations (as for example magnetic indices) and on the other hand there are modern data from satellite as ULYSSE, ACE, SOHO etc...We have now to combine old and modern data of the sun to study the various time scales of the time varying sun.

In the following 8 papers new results are presented concerning the time varying sun at different scales from event of several minutes (as solar flares), sunspot cycle, or long term variations over more than one and a half century. One paper considers astronomical parameters (the solar shape) and all the other papers are devoted to electromagnetic phenomena (solar flares, sunspot cycle, long term variations of geomagnetic activity, etc..)

Variability of the solar shape:

This paper is based on a socle of what can be known today concerning the consequences of physics of the variability of solar rotation rate and of the non uniform distribution of solar mass, on the solar limb. It emphasizes the need for new space dedicated astrometric missions, such as SDO (HMI instrument).

Solar flares:

In a first paper, effectiveness of solar flares to produce magnetic effects on earth is analyzed accordingly to their spectral nature and position on the solar disk using a long series of data. In a second paper the dependence on the final results on the nature of the natural external disturbances as a masking effect and the limitation of the detection method which is highly dependent on the availability of multiple observational points are shown, too.

Sunspot cycle:

A first paper describes study of solar activity sudden increase and Halloween storms of 2003 and highlights that during the declining phase of the last three solar cycles, secondary peaks have been detected 2-3years after the main peak of sunspot number.

A second paper criticizes and rejects the re-calibration of sunspot number by the observed daily range of the geomagnetic inclination proposed by other authors. 
Long term variations of the solar and geomagnetic activity:

In a first paper 100-150 years-long temperature and precipitation records from 14 meteorological stations in Romania are analyzed in connection with long-term trends in solar and geomagnetic activities, in the context of other European stations and of averages on the European, northern hemisphere, and global scale. Positive correlation coefficients (temperature) and negative ones (mean precipitation) with the solar (sunspot number) and geomagnetic (aa index) parameters were found at inter decadal timescales. Differences between local trends and average trends for larger areas are discussed. The study indicates that solar and geomagnetic activity effects are present on the 22-year Hale cycle timescale. The temperature variation on this timescale lags the solar/geomagnetic ones by 5-9 years. In a second paper the evolution of the long term variation of the aa index (1868 to 2008) is analyzed at the light of the new solar wind data obtained during the last decades. The rough ancient classification of solar geomagnetic activity, made before the existence of systematic solar wind measurements by satellite, is validate by the new in situ measurement of solar wind. Nevertheless it is now necessary to study in more details the geomagnetic activity at the light of all the new solar data from satellites as SOHO, ULYSSE etc...

Finally a paper is devoted to Kristian Birkeland

Kristian Birkeland adressed questions that had vexed scientists for decades:

Why do auroras appear overhead when the Earth's magnetic field is disturbed?

How are these phenomena connected to disturbances on the Sun?

To answer these questions Birkeland carried out advanced laboratory simulations - the famous terrella experiments, and daring campaigns in the polar regions. Some of Birkeland's main ideas dismissed for decades, where confirmed by satellites observation.

Some questions remain on debate:

Is there an influence of the solar magnetic field components (toroidal and poloidal) on the climate? and what is it?

We know that the Milankovitch's astronomical theory can explain by changes in geometric characteristics (eccentricity, precession and obliquity) of the earth's orbit the cycles of 100000 years, 22000 years and 41000 years in the global temperature, but they can not explain the little ice age (decrease of temperature) observe in Europe during the Maunder's minimum from 1645 to 1715 associated to a disappearance of the sunspots.

How does geomagnetic activity represent the time varying sun? What is the real increase of geomagnetic activity? 